\title{
Alarming blood pressure changes during routine bladder emptying in a woman with cervical spinal cord injury
}

\author{
Amanda H.X. Lee $\mathbb{1}^{1,2}$ - Aaron A. Phillips ${ }^{1,3,4}$ • Jordan W. Squair, ${ }^{1,5}$ Otto F. Barak ${ }^{6}$ - Geoff B. Coombs $\mathbb{1}^{7,8}$. \\ Philip N. Ainslie ${ }^{7,8} \cdot$ Zoe K. Sarafis $^{1} \cdot$ Tanja Mijacika $^{9} \cdot$ Diana Vucina $^{10} \cdot$ Zeljko Dujic $^{9} \cdot$ Andrei V. Krassioukov $^{1,2,11,12}$
}

Received: 31 August 2017 / Revised: 10 October 2017 / Accepted: 10 October 2017

(C) International Spinal Cord Society 2017

\begin{abstract}
Introduction Many individuals with high-level spinal cord injury (SCI) experience secondary conditions such as autonomic dysreflexia (AD), which is a potentially life-threatening condition comprising transient episodes of hypertension up to $300 \mathrm{mmHg}$. $\mathrm{AD}$ may be accompanied by symptoms and signs such as headache, flushing, and sweating. Delay in $\mathrm{AD}$ recognition and management is associated with increased incidence of cardiovascular events and disease. As it is commonly triggered by bladder distension, $\mathrm{AD}$ continues to be a major concern for individuals living with $\mathrm{SCI}$, both on a daily basis and in the long-term.

Case presentation A 58-year-old woman with C3 AIS B SCI presented with low resting blood pressure (BP) at 100/64 mmHg. She reported frequent episodes of $\mathrm{AD}$ that were most commonly attributed to urinary bladder filling. During our testing session, her systolic BP rose to $130 \mathrm{mmHg}$, at which point her care aide stepped in to utilize the Credé maneuver, which was part of her daily routine for bladder emptying. Application of suprapubic pressure further elevated her systolic BP to $230 \mathrm{mmHg}$. Throughout the episode of AD, the participant experienced a pounding headache and erythema above the LOI.

Discussion Clinical guidelines for bladder management after SCI recommend avoiding the Credé maneuver due to potential complications such as hernia or bruising. This current case report demonstrates the additional risk of inducing AD and dangerously high BP elevation.
\end{abstract}

\section{Introduction}

Autonomic dysreflexia (AD) is a life-threatening condition that occurs in individuals with high-level spinal cord injury (SCI), particularly in cervical SCI [1]. It is characterized by abrupt and transient episodes of hypertension: systolic

Andrei V. Krassioukov

andrei.krassioukov@vch.ca

1 International Collaboration on Repair Discoveries, Faculty of Medicine, University of British Columbia, Vancouver, BC V1Y 1T3, Canada

2 Department of Experimental Medicine, Faculty of Medicine, University of British Columbia Vancouver, Vancouver, BC V6T 1Z4, Canada

3 Department of Physiology and Pharmacology, University of Calgary, Calgary, AB T2N 1N4, Canada

4 Department of Clinical Neurosciences University of Calgary Calgary, AB T2N 1N4, Canada

5 MD/PhD Training Program, Faculty of Medicine, University of British Columbia Vancouver, Vancouver, BC V6T 1Z4, Canada blood pressure (BP) is elevated by at least $20 \mathrm{mmHg}$ and can reach up to $300 \mathrm{mmHg}[1,2]$. During AD episodes, individuals typically simultaneously experience flushing above the level of injury (LOI), sweating, anxiety, and a pounding headache $[1,2]$. AD can occur in response to both noxious and non-noxious stimuli below the LOI, including

6 University of Novi Sad School of Medicine, Novi Sad, Serbia

7 School of Health and Exercise Sciences, Faculty of Health and Social Development, University of British Columbia Okanagan, Kelowna, BC V1V 1V7, Canada

8 Centre for Heart, Lung \& Vascular Health, University of British Columbia, Kelowna, BC V1V 1V7, Canada

9 Department of Integrative Physiology, University of Split School of Medicine, Šoltanska, Split, Croatia

10 Department of Neurology, Clinical Hospital Center Split, Spinciceva, Split, Croatia

11 GF Strong Rehabilitation Centre, Vancouver Coastal Health, Vancouver, BC, Canada

12 Division of Physical Medicine \& Rehabilitation, University of British Columbia, Vancouver, BC V1V 1V7, Canada 
pressure sores, spasms, or even a tight shoelace [2]. However, the most common triggers are bladder and bowel distension [1]. Over time, untreated episodes of AD may lead to arrhythmias [3], myocardial ischemia [4], cerebral hemorrhage [5], and stroke [1]. Its relative grave consequences in the long-term make it a priority and major concern for those living with SCI. Here, we report the case of an individual with chronic SCI who experienced profound $\mathrm{AD}$ with arrhythmia triggered by use of the Credé maneuver, wherein manual pressure is applied to the lower abdomen to void the bladder.

\section{Case presentation}

Ms. $\mathrm{X}$ is a 58-year-old woman who was involved in a diving accident resulting in $\mathrm{C} 3$ motor complete sensory incomplete SCI (C3 AIS B) according to the International Standards for Neurological Classification of Spinal Cord Injury (ISNCSCI) [6]. Her injury was managed surgically and following 6 months of inpatient rehabilitation, she was discharged home. For the last 44 years since her injury, she has lived independently at home with support from a personal assistant and does not currently use any medications. As a result of her SCI, she has developed numerous secondary conditions that are typical for individuals with cervical SCI, which include the following: resting hypotension, episodes of $\mathrm{AD}$, and neurogenic bladder and bowel. Her bladder management initially started with the use of Foley catheters. However, due to frequent urinary tract infections, this was discontinued and for the last 15 years, her bladder has been expressed manually using the Credé maneuver three to four times a day. She reported that for the last 10 years she has experienced symptomatic AD with headaches of varying severity whenever her bladder was full or during her bladder management routine performed by one of her caregivers. Symptomatic AD was the only sensation that this patient considered an indication of the need to express the bladder. She also reported frequent episodes of incontinence and used adult diapers for management.

Ms. X came in as a volunteer participant for a study conducted by an international team at the University of Split, Croatia, which involved complex cardiovascular assessments of individuals with SCI. As a part of her baseline evaluation for the study she underwent neurological assessment using the ISNCSCI [6] and autonomic screening using the International Standards to document remaining Autonomic Function after Spinal Cord Injury (ISAFSCI) [7]. While completing her ISAFSCI table, we documented information regarding unstable BP control and neurogenic bladder (only relevant parts of the assessment were completed: see Fig. 1). After baseline evaluations, participants underwent complex evaluations of various cardiovascular and respiratory parameters according to the approved protocol. Ms. X was fitted with a standard 3-lead electrocardiogram (ECG) (lead II; Powerlab Model ML132) and beat-by-beat BP monitoring device (Finometer; Finapres Medical Systems BV, Arnhem, The Netherlands). Her arterial BP and ECG were recorded continuously for approximately 3 hours during various evaluations. She initially presented with low arterial BP, which was 90/51 $\mathrm{mmHg}$ with a heart rate of $82 \mathrm{bpm}$ while seated and 100/64 $\mathrm{mmHg}$ with a heart rate of $84 \mathrm{bpm}$ while supine at rest with no evidence of arrhythmia (Fig. 2a).

Approximately 2 hours after initiation of her evaluation, a gradual increase in her BP to $130 \mathrm{mmHg}$ was noted, and she complained of a slight headache. She indicated that this was a typical sign of a full bladder for her, and that she needed to conduct her bladder routine. Her caregiver assisted with bladder emptying by rhythmically applying pressure over the suprapubic area (Credé maneuver), which was done with significant impacting force. Our team continued with simultaneously monitoring her cardiovascular parameters (arterial BP, heart rate, and numerous cardiac function measures) throughout this procedure. Her already elevated systolic pressure spiked rapidly up to $230 \mathrm{mmHg}$ when pressure was applied to the abdominal wall to initiate voiding (Fig. 2b). During this procedure, Ms. X complained of a pounding headache and excessive flushing of the face was observed. This episode of AD during the Credé maneuver was also associated with multiple premature ventricular contractions (PVCs) that were recorded on her ECG (Fig. 2b). After the bladder was expressed, she was transferred to a semi-seated position until her BP gradually decreased $(125 / 89 \mathrm{mmHg})$. Her symptoms resolved with her arterial BP returning to baseline.

\section{Discussion}

Presently, it is acknowledged that motor and sensory deficits should be evaluated when examining a person with SCI. Over the last decade, international efforts have contributed to developing standards for evaluating autonomic functions that are currently represented by the ISAFSCI table (2012) [7]. In this clinical case, the ISAFSCI effectively collected crucial information related to the severity of Ms. X's AD. Although a novel tool, the ISAFSCI has demonstrated numerous clinical advantages and reliability for evaluating autonomic function after SCI: currently it is used to document the presence of conditions exhibited after SCI, such as AD or orthostatic hypotension [8, 9]. The present form of ISAFSCI does not quantify severity of autonomic dysfunction (i.e. using BP levels). Inclusion of this domain by categorizing severity of AD using discrete categories based on $\mathrm{BP}$ have been suggested by clinicians to improve the 
Patient Name: Ms. X

\begin{tabular}{|c|c|c|c|}
\hline System/Organ & Findings & Abnormal conditions & $\begin{array}{l}\text { Check } \\
\text { mark }\end{array}$ \\
\hline \multirow{6}{*}{$\begin{array}{l}\text { Autonomic } \\
\text { control of the } \\
\text { heart }\end{array}$} & Normal & & \\
\hline & \multirow[t]{3}{*}{ Abnormal } & Bradycardia & $X$ \\
\hline & & Tachycardia & \\
\hline & & Other dysrhythmias & $\mathrm{X}$ \\
\hline & Unknown & & \\
\hline & $\begin{array}{l}\text { Unable to } \\
\text { assess }\end{array}$ & & \\
\hline \multirow{6}{*}{$\begin{array}{l}\text { Autonomic } \\
\text { control of } \\
\text { blood } \\
\text { pressure }\end{array}$} & Normal & & \\
\hline & \multirow[t]{3}{*}{ Abnormal } & $\begin{array}{l}\text { Resting systolic blood } \\
\text { pressure below } 90 \mathrm{mmHg}\end{array}$ & $\mathrm{X}$ \\
\hline & & Orthostatic hypotension & \\
\hline & & Autonomic dysreflexia & $\mathrm{X}$ \\
\hline & Unknown & & \\
\hline & $\begin{array}{l}\text { Unable to } \\
\text { assess }\end{array}$ & & \\
\hline \multirow{6}{*}{$\begin{array}{l}\text { Autonomic } \\
\text { control of } \\
\text { sweating }\end{array}$} & Normal & & \\
\hline & \multirow[t]{3}{*}{ Abnormal } & Hyperhydrosis above lesion & \\
\hline & & Hyperhydrosis below lesion & \\
\hline & & Hypohydrosis below lesion & \\
\hline & Unknown & & \\
\hline & $\begin{array}{l}\text { Unable to } \\
\text { assess }\end{array}$ & & \\
\hline \multirow{5}{*}{$\begin{array}{l}\text { Temperature } \\
\text { regulation }\end{array}$} & Normal & & \\
\hline & \multirow[t]{2}{*}{ Abnormal } & Hyperthermia & \\
\hline & & Hypothermia & \\
\hline & Unknown & & \\
\hline & $\begin{array}{l}\text { Unable to } \\
\text { assess }\end{array}$ & & \\
\hline \multirow{6}{*}{$\begin{array}{l}\text { Autonomic } \\
\text { and Somatic } \\
\text { Control } \\
\text { of Broncho- } \\
\text { pulmonary } \\
\text { System }\end{array}$} & Normal & & \\
\hline & \multirow[t]{3}{*}{ Abnormal } & $\begin{array}{l}\text { Unable to voluntarily breathe } \\
\text { requiring full ventilatory } \\
\text { support }\end{array}$ & \\
\hline & & $\begin{array}{l}\text { Impaired voluntary breathing } \\
\text { requiring partial vent support }\end{array}$ & \\
\hline & & $\begin{array}{l}\text { Voluntary respiration } \\
\text { impaired does not require } \\
\text { vent support }\end{array}$ & \\
\hline & Unknown & & \\
\hline & $\begin{array}{l}\text { Unable to } \\
\text { assess }\end{array}$ & & \\
\hline
\end{tabular}

\begin{tabular}{|c|c|}
\hline System/Organ & Score \\
\hline \multicolumn{2}{|l|}{ Lower Urinary Tract } \\
\hline $\begin{array}{l}\text { Awareness of the need to empty the } \\
\text { bladder }\end{array}$ & 0 \\
\hline Ability to prevent leakage (continence) & 0 \\
\hline Bladder emptying method (specify) & $\begin{array}{l}\text { Credé } \\
\text { Maneuver }\end{array}$ \\
\hline \multicolumn{2}{|l|}{ Bowel } \\
\hline \multicolumn{2}{|l|}{$\begin{array}{l}\text { Sensation of need for a bowel } \\
\text { movement }\end{array}$} \\
\hline \multicolumn{2}{|l|}{$\begin{array}{l}\text { Ability to Prevent Stool Leakage } \\
\text { (Continence) }\end{array}$} \\
\hline \multicolumn{2}{|l|}{ Voluntary sphincter contraction } \\
\hline \multicolumn{2}{|l|}{ Sexual Function } \\
\hline \multirow{2}{*}{$\begin{array}{l}\text { Genital arousal } \\
\text { Psychogenic } \\
\text { (erection or lubrication) } \\
\text { Reflex }\end{array}$} & \\
\hline & \\
\hline \multicolumn{2}{|l|}{ Orgasm } \\
\hline \multicolumn{2}{|l|}{ Ejaculation (male only) } \\
\hline Sensation of Menses (female only) & \\
\hline
\end{tabular}

2=Normal function, 1=Reduced or Altered Neurological Function

$0=$ Complete loss of control, NT=Unable to assess due to preexisting or concomitant problems
Fig. 1 Autonomic standards assessment form according to the International Standards to document remaining Autonomic Function after Spinal Cord Injury (ISAFSCI) [8]. The form was completed following assessment and interview of this 58-year-old woman with C3 AIS B (motor complete, sensory incomplete) SCI. Based on her interview and evaluation we documented the following sections: low resting blood

ISAFSCI for version 3 [9]. While assessing autonomic functions, clinicians and scientists also must consider existing international SCI datasets for assessment of autonomic dysfunction following SCI, including datasets for cardiovascular function [10], skin/thermoregulation [11], pulmonary function [12], lower urinary tract [13], and bowel function [14].

The Credé maneuver is a method of manually expressing urine from the bladder by applying suprapubic pressure [15]. The Valsalva maneuver is an alternative technique wherein abdominal muscles and the diaphragm are voluntarily activated by the individual to express the bladder [15]. pressure, autonomic dysreflexia (AD), bradyarrhythmia, neurogenic bladder with no sensation of filling, and no ability to prevent leakage. Only parameters related to the issues described in the case were completed, as denoted by (x) in the corresponding areas. The Credé maneuver was used for bladder management.

Both of these maneuvers result in increased intraabdominal pressure and consequently bladder expression. Although both methods are described in the Paralyzed Veterans of America Clinical Practice guidelines, they are only recommended for individuals with lower motor neuron injuries with low outlet resistance and external sphincter resistance. Additionally, it is suggested to consider avoiding these methods as the primary method of bladder emptying due to potential complications such as incomplete emptying, abdominal bruising, inguinal hernias, and hydronephrosis [15-17]. As demonstrated by this case, $\mathrm{AD}$ is also a major complication that can result from manual pressure being 


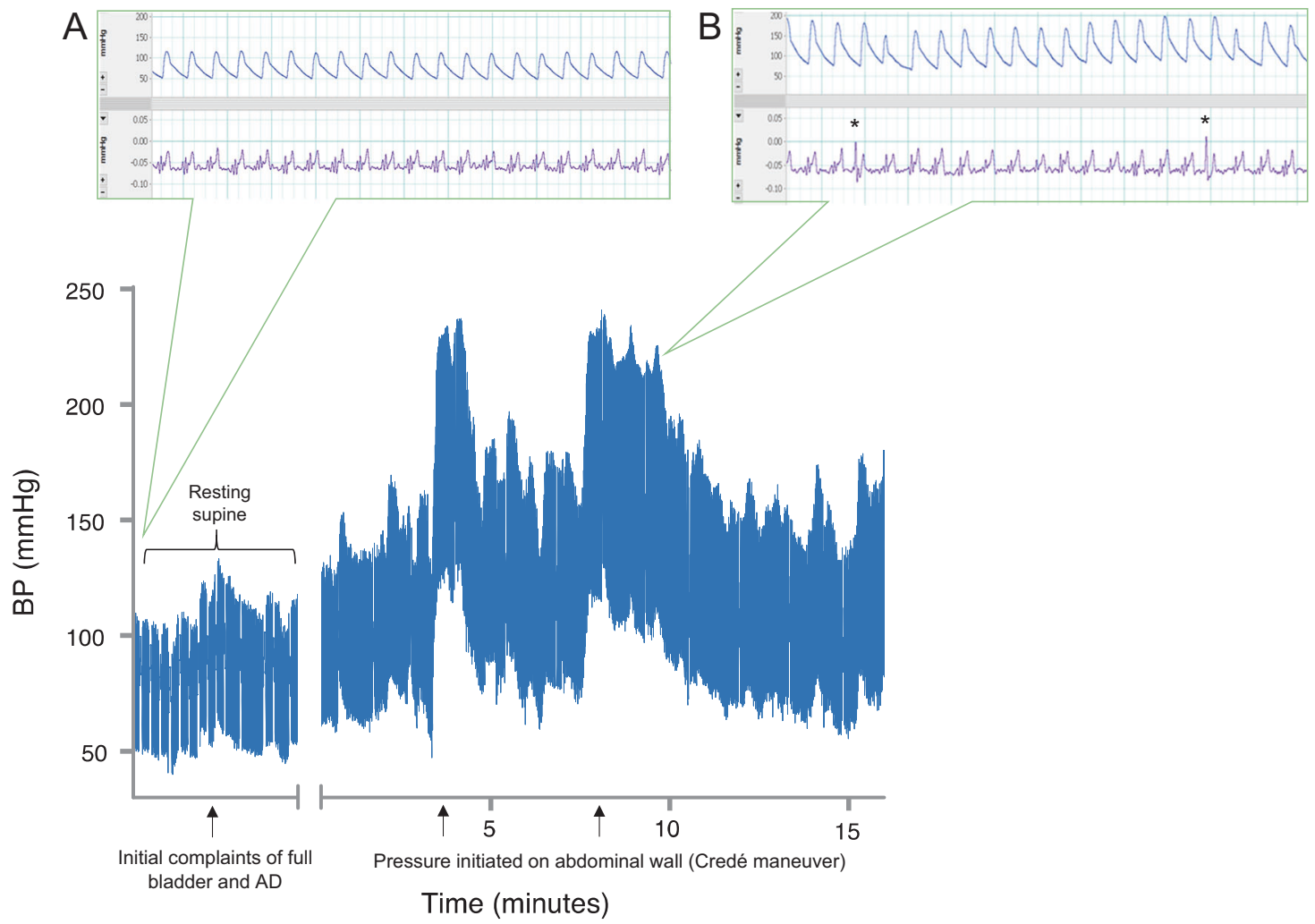

Fig. 2 Blood pressure elevation and electrocardiogram abnormalities upon bladder distension and emptying. Differences were observed in beat-by-beat blood pressure (BP) and electrocardiogram (ECG) between baseline condition and during bladder filling and emptying via the Credé maneuver. Baseline supine systolic BP was $100 \mathrm{mmHg}$ with normal ECG trace as shown in a 25-s excerpt (a). Elevation in systolic $\mathrm{BP}$ occurred due to bladder distension. When systolic BP reached 130

applied on the abdominal wall for bladder expression in individuals with cervical SCI.

The primary underlying mechanisms of development of $\mathrm{AD}$ involve an excessive sympathetic discharge of spinal autonomic circuits that lack descending inhibition due to disruption of the spinal pathways [18]. Numerous studies have previously documented various cardiac arrhythmias associated with episodes of $\mathrm{AD}$, including atrial fibrillation [3], premature atrial contractions [19], and bradycardia [20]. In this case, multiple PVCs were observed throughout the bouts of AD, with bradycardia of $55 \mathrm{bpm}$. PVCs are associated with sudden cardiac death, providing another potential link between $\mathrm{AD}$ and the augmented risk for cardiac mortality in those living with SCI [21].

Given the fact that bladder irritation and distension are the most prevalent triggers of $\mathrm{AD}$, bladder care optimization for individuals living with SCI is critical to minimizing incidence of $\mathrm{AD}$ and managing episodes. This is particularly important for individuals with cervical or high-thoracic SCI who are prone to greater impairment of cardiovascular function and more severe episodes of $\mathrm{AD}[1,22,23]$.
$\mathrm{mmHg}$, the patient reported a headache and flushing of the face was observed. Initiation of rhythmic pressure to the abdomen caused an immediate rise in systolic BP above $200 \mathrm{mmHg}$ consistent with the episode of autonomic dysreflexia (AD). Premature ventricular contraction (PVC) occurred concurrently with bradycardia during the $\mathrm{AD}$ episode, as denoted by (*) and shown in a 25 -s excerpt (b)

Currently, clean intermittent catheterization is considered the gold standard for management of neurogenic bladder following SCI [24, 25]. In individuals with impaired hand function or limited assistance from caregivers, other options which can be considered include urethral indwelling or suprapubic catheters [26]. These methods of bladder management provide continuous urine outflow and decrease the bladder distension and consequently episodes of $\mathrm{AD}$ [15]. However, regular surveillance and follow-up by a urologist is required with these catheters due to increased risk of bladder cancer [15]. Although no longer as common in North America, the Credé technique is still currently practiced for individuals with SCI in a number of countries around the world. Greater outreach is required to establish the benefits vs. risks of this practice and mitigate its use.

In conclusion, this case provides additional evidence for the importance of selecting the optimal bladder management protocol for each individual with SCI to accomplish efficient and safe urine evacuation without triggering lifethreatening episodes of AD. 
Acknowledgements The authors would like to acknowledge the individual who participated in these assessments and consented to publication of her case. A.A.P., J.W.S., P.N.A., and G.B.C. were supported by a Seed Grant from the International Collaboration on Repair Discoveries (ICORD). Z.K.S. and A.H.X.L. were supported by the UBC Go Global Self-Directed Research Award. A.H.X.L. is supported by the Canadian Institutes of Health Research and the Craig Neilsen Foundation. A.V.K. is supported by the Craig Neilsen Foundation, Canadian Institutes of Health Research, the Heart \& Stroke Foundation, and the Rick Hansen Institute.

\section{Compliance with ethical standards}

Conflict of interest The authors declare that they have no competing interests.

\section{References}

1. Wan D, Krassioukov AV. Life-threatening outcomes associated with autonomic dysreflexia: a clinical review. J Spinal Cord Med. 2014;37:2-10. http://www.ncbi.nlm.nih.gov/pubmed/24090418. Accessed 24 Nov 2016.

2. Phillips AA, Krassioukov AV. Contemporary cardiovascular concerns after spinal cord injury: mechanisms, maladaptations, and management. J Neurotrauma. 2015;32:1927-42. http://www. ncbi.nlm.nih.gov/pubmed/25962761.

3. Pine ZM, Miller SD, Alonso JA. Atrial fibrillation associated with autonomic dysreflexia. Am J Phys Med Rehabil. 1991;70:271-3. http://www.ncbi.nlm.nih.gov/pubmed/1910653.

4. Ho CP, Krassioukov AV. Autonomic dysreflexia and myocardial ischemia. Spinal Cord. 2010;48:714-5. http://www.ncbi.nlm.nih. gov/pubmed/20125109.

5. Pan S-L, Wang Y-H, Lin H-L, Chang C-W, Wu T-Y, Hsieh E-T. Intracerebral hemorrhage secondary to autonomic dysreflexia in a young person with incomplete C8 tetraplegia: a case report. Arch Phys Med Rehabil. 2005;86:591-3. http://www.ncbi.nlm.nih.gov/ pubmed/15759250.

6. Kirshblum SC, Burns SP, Biering-Sorensen F, Donovan W, Graves DE, Jha A, et al. International standards for neurological classification of spinal cord injury (Revised 2011). J Spinal Cord Med. 2011;34:535-46. http://www.ncbi.nlm.nih.gov/pubmed/ 22330108. Accessed 15 Aug 2017.

7. Krassioukov A, Biering-Sørensen F, Donovan W, Kennelly M, Kirshblum S, Krogh K, et al. International Standards to document remaining Autonomic Function after Spinal Cord Injury. J Spinal Cord Med. 2012;35:201-10. http://www.ncbi.nlm.nih.gov/ pubmed/22925746. Accessed 7 Jul 2017.

8. Davidson RA, Carlson M, Fallah N, Noonan VK, Elliott SL, Joseph J, et al. Inter-rater reliability of the International Standards to document remaining Autonomic Function after Spinal Cord Injury. J Neurotrauma. 2017;34:552-8. http://online.liebertpub. com/doi/10.1089/neu.2016.4489. Accessed 7 Jul 2017.

9. Round AM, Park SE, Walden K, Noonan VK, Townson AF, Krassioukov AV. An evaluation of the International Standards to document remaining Autonomic Function after Spinal Cord Injury: input from the international community. Spinal Cord. 2017;55:198-203. http://www.ncbi.nlm.nih.gov/pubmed/ 27897184.

10. Krassioukov A, Alexander MS, Karlsson AK, Donovan W, Mathias CJ, Biering-Sørensen F. International spinal cord injury cardiovascular function basic data set. Spinal Cord. 2010;48:586-90. http://www.ncbi.nlm.nih.gov/pubmed/20101250.
11. Karlsson AK, Krassioukov A, Alexander MS, Donovan W, Biering-Sørensen F. International spinal cord injury skin and thermoregulation function basic data set. Spinal Cord. 2012;50:512-6. http://www.ncbi.nlm.nih.gov/pubmed/22289898.

12. Biering-Sørensen F, Krassioukov A, Alexander MS, Donovan W, Karlsson A-K, Mueller G, et al. International spinal cord injury pulmonary function basic data set. Spinal Cord. 2012;50:418-21. http://www.ncbi.nlm.nih.gov/pubmed/22270192. Accessed 10 Oct 2017

13. Biering-Sørensen F, Craggs M, Kennelly M, Schick E, Wyndaele J-J. International lower urinary tract function basic spinal cord injury data set. Spinal Cord 2008;46:325-30. http://www.ncbi. nlm.nih.gov/pubmed/18040278. Accessed 10 Oct 2017.

14. Krogh K, Emmanuel A, Perrouin-Verbe B, Korsten MA, Mulcahey MJ, Biering-Sørensen F. International spinal cord injury bowel function basic data set (Version 2.0). Spinal Cord. 2017;55:692-8. http://www.ncbi.nlm.nih.gov/pubmed/28195229.

15. Consortium for Spinal Cord Medicine. Bladder management for adults with spinal cord injury: a clinical practice guideline for health-care providers. J Spinal Cord Med 2006;29:527-73. http:// www.ncbi.nlm.nih.gov/pubmed/17274492.

16. Chang SM, Hou CL, Dong DQ, Zhang H. Urologic status of 74 spinal cord injury patients from the 1976 Tangshan earthquake, and managed for over 20 years using the Credé maneuver. Spinal Cord. 2000;38:552-4. http://www.ncbi.nlm.nih.gov/pubmed/ 11035477.

17. Weld KJ, Dmochowski RR. Effect of bladder management on urological complications in spinal cord injured patients. J Urol [Internet]. 2000;163:768-72. http://www.ncbi.nlm.nih.gov/ pubmed/10687973.

18. McGregor JA, Meeuwsen J. Autonomic hyperreflexia: a mortal danger for spinal cord-damaged women in labor. Am J Obstet Gynecol. 1985;151:330-3. http://www.ncbi.nlm.nih.gov/pubmed/ 3970101. Accessed 27 Nov 2016.

19. Claydon VE, Elliott SL, Sheel AW, Krassioukov A. Cardiovascular responses to vibrostimulation for sperm retrieval in men with spinal cord injury. J Spinal Cord Med 2006;29:207-16. http:// www.ncbi.nlm.nih.gov/pubmed/16859224. Accessed 6 July 2017.

20. Hagen EM, Faerestrand S, Hoff JM, Rekand T, Gronning M. Cardiovascular and urological dysfunction in spinal cord injury. Acta Neurol Scand Suppl 2011; 191:71-8. Available from: http:// www.ncbi.nlm.nih.gov/pubmed/21711260.

21. Ataklte F, Erqou S, Laukkanen J, Kaptoge S. Meta-analysis of ventricular premature complexes and their relation to cardiac mortality in general populations. Am J Cardiol. 2013;112:1263-70. http://www.ncbi.nlm.nih.gov/pubmed/23927786.

22. West CR, Mills P, Krassioukov AV. Influence of the neurological level of spinal cord injury on cardiovascular outcomes in humans: a meta-analysis. Spinal Cord. 2012;50:484-92.

23. Sheel AW, Krassioukov AV, Inglis JT, Elliott SL. Autonomic dysreflexia during sperm retrieval in spinal cord injury: influence of lesion level and sildenafil citrate. J Appl Physiol. 2005;99:53-8. http://jap.physiology.org/cgi/doi/10.1152/japplphysiol.00154. 2005. Accessed 7 Jul 2017.

24. Di Benedetto P. Clean intermittent self-catheterization in neurourology. Eur J Phys Rehabil Med. 2011;47:651-9. http://www. ncbi.nlm.nih.gov/pubmed/21711260.

25. Sorokin I, De E. Options for independent bladder management in patients with spinal cord injury and hand function prohibiting intermittent catheterization. Neurourol Urodyn. 2015;34:167-76. http://www.ncbi.nlm.nih.gov/pubmed/24151101.

26. Al Taweel W, Seyam R. Neurogenic bladder in spinal cord injury patients. Res Rep Urol. 2015;7:85-99. http://www.ncbi.nlm.nih. gov/pubmed/26090342. 